\title{
Preoperative Liver Function Guiding HCC Resection in Normal and Cirrhotic Liver
}

\author{
Friedrich Anger ${ }^{a}$ Ingo Klein ${ }^{a}$ Stefan Löb ${ }^{a}$ Armin Wiegering ${ }^{a}$ \\ Gurinder Singh ${ }^{a}$ Dominique Sperl ${ }^{a}$ Oliver Götze ${ }^{b}$ Andreas Geier ${ }^{b}$ \\ Johan Friso Lock ${ }^{\mathrm{a}}$ \\ a Department of General, Visceral and Transplantation Surgery, University Hospital of Würzburg, Würzburg,

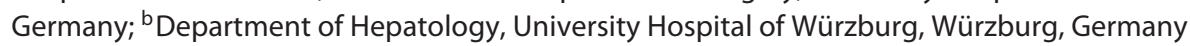

\section{Keywords}

Hepatocellular carcinoma · Cirrhosis - Liver function ·

Postoperative liver failure $\cdot$ Liver surgery $\cdot 13 \mathrm{C}$ breath test

\begin{abstract}
Background: Liver resection is the most effective available therapy for patients with hepatocellular carcinoma (HCC). The accurate selection of patients for surgery requires determination of technical resectability and the risk of recurrence, as well as assessment of liver function and functional reserve to avoid postoperative liver failure. Previous studies have underlined the effectiveness and reliability of the LiMAx ${ }^{\circledR}$ test to evaluate liver function preoperatively. Nevertheless, data concerning HCC evaluation are lacking. Methods: From 2014 to 2019, 92 patients with HCC underwent additional assessment of liver function using the LiMAx test prior to decision for or against liver resection. Preoperative LiMAx results were compared between cirrhotic and noncirrhotic liver. The clinical decision for surgery was evaluated applying the various liver function parameters available. Results: Forty-six patients underwent liver resection. The LiMAx results were higher in resected patients (388 vs. $322 \mu \mathrm{g} / \mathrm{kg} / \mathrm{h} ; p=$ 0.004). LiMAx values were an independent risk factor for the presence of liver cirrhosis in multivariate analysis. In 17 patients, surgical treatment was cancelled due to major impairment of liver function. Only 4 out of 46 resected patients presented with post-hepatectomy liver failure (PHLF) grade $\geq B$. Histologic assessment revealed liver cirrhosis in 10 resected
\end{abstract}

karger@karger.com www.karger.com/vis

Karger 马OPEN ACCESS
(C) 2019 The Author(s)

Published by S. Karger AG, Base

This is an Open Access article licensed under the Creative Common Attribution-NonCommercial-4.0 International License (CC BY-NC) (http://www.karger.com/Services/OpenAccessLicense), applicable to the online version of the article only. Usage and distribution for commercial purposes requires written permission. patients without PHLF. Conclusion: Preoperative determination of liver function by the LiMAx test enables effective and safe patient selection for HCC resection in both cirrhotic and noncirrhotic liver.

(c) 2019 The Author(s) Published by S. Karger AG, Basel

\section{Introduction}

Liver resection has remained the treatment of choice for most patients suffering from hepatocellular carcinoma (HCC). Liver resection improves mean survival across all Barcelona Clinic Liver Cancer (BCLC) stages more effectively than all nonsurgical therapy options, such as radiofrequency ablation or transarterial chemoembolization [1-4]. Furthermore, a recent meta-analysis has shown similar 5-year overall survival after resection in comparison to transplantation in patients eligible for liver transplantation [5]. Although resection is associated with a significantly lower disease-free survival in comparison to transplantation and a continuous risk of de novo HCC in liver cirrhosis, it remains the favorable firstline therapy in times of organ shortage $[6,7]$.

Nevertheless, post-hepatectomy liver failure (PHLF) remains a major cause of postoperative mortality, especially in the presence of underlying cirrhosis [8-10]. Therefore, effective HCC therapy and evaluation of hepatic resection requires an individualized selection process on a multidisciplinary basis, including risk factors of postoperative mor- 
bidity and mortality as well prognostic factors concerning overall and disease-free survival $[2,11]$.

Several preoperative evaluation strategies to avoid PHLF in HCC have been reported. Common scoring systems to assess disease severity, for example, the model of end-stage liver disease (MELD score), fail to provide individual precision [12]. Therefore, several dynamic liver function tests have been evaluated for preoperative assessment of functional reserve. Of those, the indocyanine green elimination test (ICG test) has been the most frequently reported test $[13,14]$. Recently, evidence has emerged that perioperative assessment of functional reserve by the LiMAx ${ }^{\circledR}$ test reduces severe postoperative complications [15]. However, there is a lack of studies describing application of the LiMAx test in patients with HCC. Blüthner et al. [16] reported that calculation of future liver remnant function using the LiMAx test was superior to calculation of future liver remnant volume in the prognosis of PHLF in high-risk patients with HCC in cirrhosis.

The aim of this study was to evaluate the efficacy of the LiMAx test in preoperative evaluation of HCC patients.

\section{Patients and Methods}

\section{Study Design}

We performed a retrospective analysis of our patient cohort. Inclusion criteria were histologically proven or radiologically suspected HCC by 2 different methods, typically by a contrast-enhanced three-phase CT and high-quality MRI of the liver. Exclusion criteria were postoperative histopathological exclusion of HCC. All data were extracted from our electronic hospital information system and were transferred in an anonymized database.

Indication for resection surgery was set individually for each case in our interdisciplinary conference on the basis of the patients' general condition, tumor extent, portal hypertension, and functional reserve. Portal hypertension was defined by the presence of splenomegaly with thrombocytopenia or esophageal varices. Spleen size was measured by the longitudinal (cranio-caudal) diameter in cross-section imaging. The resection strategy was based on the location and extent of the HCC, the individual liver anatomy, the preoperative liver function (including the LiMAx ${ }^{\circledR}$ test), and the individual performance status.

\section{Preoperative Evaluation of Functional Reserve}

The preoperative patient evaluation in our department has included the LiMAx ${ }^{\circledR}$ test according to the algorithm of Stockmann et al. [17] since 2014. In addition, liver function was assessed by biochemical evaluation (including transaminases, bilirubin, albumin, Quick and INR, and creatinine). All patients were diagnosed and staged thoroughly in terms of radiologic imaging, increased AFP, and comorbid conditions.

The LiMAx test was performed as described previously [18]. The test substrate ${ }^{13} \mathrm{C}$-methacetin $(2 \mathrm{mg} / \mathrm{kg}$ intravenously; $\mathrm{Hu}-$ medics $\mathrm{GmbH}$, Berlin, Germany) is administered and specifically metabolized by hepatocytes in the microsomal cytochrome P450 $1 \mathrm{~A} 2$ enzyme system. Thus, the emerging ${ }^{13} \mathrm{CO}_{2}$ is exhaled leading to a measurable alteration of ${ }^{13} \mathrm{CO}_{2} /{ }^{12} \mathrm{CO}_{2}$ ratio in the patient's breath (FLIP ${ }^{\circledR}$; Humedics). The LiMAx test result (in $\mu \mathrm{g} / \mathrm{kg} / \mathrm{h}$ ) is calculated by the device and provided within 20 min to a maximum of $60 \mathrm{~min}$ after substrate administration. LiMAx values $>315 \mu \mathrm{g} /$ $\mathrm{kg} / \mathrm{h}$ are considered normal [19].

\section{Statistical Analysis}

Patients were dichotomized during statistical analysis into 2 groups: patients diagnosed with liver cirrhosis (LC group) and those with normal liver (NL group). The diagnosis of liver cirrhosis was primarily based on histopathological staining, either of percutaneous liver biopsy or tumor-free tissue margins of resected HCCs. Those patients without available tissue samples were analyzed by imaging for the diagnosis of liver cirrhosis, including transient elastography, ultrasound, CT, and MRI [20, 21]. Accordingly, the NL group consisted of patients with normal liver morphology. The 2 groups were compared to each other in terms of baseline characteristics (sex, age, BMI, laboratory results, spleen size, BCLC), LiMAx values, and resection surgery.

Subsequently, patients receiving resection surgery were evaluated in terms of postoperative complications, PHLF, length of stay in intensive care, and length of hospital stay. Postoperative complications were graded according to the classification by Clavien and Dindo [22]. PHLF was defined according to the definition of the International Study Group of Liver Surgery [23].

Descriptive data are shown as median with range or total with percent (unless otherwise indicated). Univariate analysis was either done by $\chi^{2}$, Fisher's exact, or Mann-Whitney U test in according to the data scale and distribution. Pre- and intraoperative variables that were statistically significant in the univariate analysis $(p$ value $<0.05$ ) were included into a stepwise backwards multivariate logistic regression model. The prognostic value of liver function variables predicting insufficient functional liver reserve was assessed using receiver operating characteristic (ROC) curve analysis. The level of significance was $p<0.05$ (two-sided). The analyses were performed using IBM SPSS Statistics version 25.

\section{Results}

\section{Patient Characteristics}

A total of 92 patients diagnosed with $\mathrm{HCC}$ received the LiMAx ${ }^{\circledR}$ test during evaluation of surgical treatment. Forty-three (47\%) of these patients were diagnosed with liver cirrhosis (LC group), whereas 49 (53\%) patients, without evidence of cirrhosis, were assigned to the NL group). Gender, age, and BMI were distributed equally in both groups. LiMAx results in the LC group were significantly lower compared to those in the NL group (265 [19$523]$ vs. 431 [163-841] $\mu \mathrm{g} / \mathrm{kg} / \mathrm{h}, p<0.001)$. Significant differences in laboratory results of serum bilirubin, albumin, and INR confirmed hepatic impairment in the LC group $(p<0.001)$. Consequently, when calculating the values according to the laboratory model of end-stage liver disease (labMELD), a significant difference between groups could be observed. Stratification for platelet count and spleen size resulted in a significant lower platelet count and bigger spleen size in the LC group. In multivariate analysis $\operatorname{LiMAx}^{\circledR}$ values, serum albumin, and platelet count could be identified as independent risk factors for the presence of liver cirrhosis (data not shown). 
Table 1. Demographics of total cohort and differences between patients with and without liver cirrhosis

\begin{tabular}{|c|c|c|c|c|}
\hline & Total & LC group & NL group & $p$ value \\
\hline Patients & $92(100)$ & $43(46.7)$ & $49(53.3)$ & \\
\hline Male gender & $73(79.3)$ & $34(79.1)$ & $39(79.6)$ & \\
\hline Age, years & $65(43-88)$ & $63(43-85)$ & $68(47-88)$ & $0.068^{\mathrm{a}}$ \\
\hline $\mathrm{BMI}, \mathrm{kg} / \mathrm{m}^{2}$ & $26.5(18-46)$ & $28(18-46)$ & $26(18-35)$ & \\
\hline LiMAx, $\mu g / k g / h$ & $354(19-841)$ & $265(19-523)$ & $431(163-841)$ & $0.001^{\mathrm{a}}$ \\
\hline Bilirubin, mg/dL & $0.7(0.2-7.0)$ & $1.0(0.2-4.1)$ & $0.5(0.2-7.0)$ & $0.001^{\mathrm{a}}$ \\
\hline Albumin, g/dL & $4.2(2.8-5.1)$ & $4.1(3.8-4.9)$ & $4.4(3.1-5.1)$ & $0.001^{\mathrm{a}}$ \\
\hline INR & $1.05(0.88-2.4)$ & $1.15(0.97-2.43)$ & $1.0(0.88-2.15)$ & $0.001^{\mathrm{a}}$ \\
\hline Platelet count, $\times 10^{3} / \mu \mathrm{L}$ & $184(51-534)$ & $131(51-340)$ & $203(128-534)$ & $0.001^{\mathrm{a}}$ \\
\hline Spleen size, $\mathrm{cm}$ & $11.2(6.9-16.6)$ & $12.5(7.9-16.6)$ & $10.1(6.9-15.3)$ & $0.001^{\mathrm{a}}$ \\
\hline History of alcohol abuse & $29(31.5)$ & $24(55.8)$ & $5(10.2)$ & $0.001^{\mathrm{b}}$ \\
\hline Hepatitis & $28(30.4)$ & $12(27.9)$ & $16(32.7)$ & $0.57^{\mathrm{b}}$ \\
\hline Unifocal lesions & $64(69.6)$ & $27(62.8)$ & $37(75.5)$ & $0.19^{\mathrm{b}}$ \\
\hline Multifocal lesions & $28(30.4)$ & $16(37)$ & $12(24.5)$ & \\
\hline Size lesion, $\mathrm{cm}$ & $5.2(1-22)$ & $3.95(1-17.4)$ & $6.5(1.3-22)$ & $0.004^{\mathrm{a}}$ \\
\hline $\mathrm{AFP}, \mu \mathrm{g} / \mathrm{L}$ & $7.3(1.7-60,500)$ & $20(2.2-60,500)$ & $4.8(1.7-21,000)$ & $0.001^{\mathrm{a}}$ \\
\hline \multicolumn{5}{|l|}{ Child-Pugh score } \\
\hline $\mathrm{A}$ & & $34(81)$ & & \\
\hline B & & $7(16.7)$ & & \\
\hline C & & $1(2.4)$ & & \\
\hline labMELD & $7(6-19)$ & $8(6-19)$ & $7(6-15)$ & $0.001^{\mathrm{a}}$ \\
\hline \multicolumn{5}{|l|}{ BCLC } \\
\hline 0 & $2(2.2)$ & $1(2.3)$ & $1(2)$ & \\
\hline $\mathrm{A}$ & $41(44.6)$ & $23(53.5)$ & $18(36.7)$ & \\
\hline $\mathrm{B}$ & $36(39.1)$ & $12(30.2)$ & $23(46.9)$ & \\
\hline $\mathrm{C}$ & $11(12)$ & $4(9.3)$ & $7(14.3)$ & \\
\hline $\mathrm{D}$ & $2(2.2)$ & $2(4.7)$ & & \\
\hline Resection & $46(50)$ & $13(30.2)$ & $33(67.3)$ & $0.001^{\mathrm{b}}$ \\
\hline Resection type & & & & $0.61^{\mathrm{b}}$ \\
\hline 1-3 liver segments & $22(47.8)$ & $7(54)$ & $15(45.2)$ & \\
\hline$\geq 4$ liver segments & $24(52.2)$ & $6(46)$ & $18(54.5)$ & \\
\hline
\end{tabular}

Data are presented as $n$ (\%) or median (range), as appropriate. LC group, liver cirrhosis group; NL group, normal liver group. ${ }^{\mathrm{a}}$ Man-Whitney $\mathrm{U}$ test; ${ }^{\mathrm{b}} \chi^{2}$ test.

Patients in both groups were equally attributed to the different stages by the BCLC system. Measurements of the associated tumor AFP resulted in markedly higher values $(20[2.2-605,000]$ vs. $4.8[1.7-21,000] \mu \mathrm{g} / \mathrm{L}, p=0.001)$ in the LC group. While patients in the LC group suffered from multifocal disease more often $(p=0.19)$, patients with normal liver morphology developed significantly larger tumors $(3.95[1-17.4]$ vs. $6.5[1.3-22] \mathrm{cm}, p=$ 0.004). Table 1 presents all patients' characteristics divided into the 2 different patient cohorts.

\section{Treatment}

After evaluation of functional reserve and interdisciplinary discussion, 46 (50\%) patients underwent HCC resection, 13 out of the LC group and 33 out of the NL group $(p=0.004) ; 22(48 \%)$ patients underwent anatomical resection of 1-3 liver segments and $24(52 \%)$ patients underwent resection of 4 or more liver segments ( 6 in the LC group and 18 in the NL group). Age and BMI were distributed equally between the patients resected and those otherwise treated. The median age at operation was 65 years (43-81). In patients undergoing surgery, LiMAx ${ }^{\circledR}$ results were significantly higher $(388$ [127-841] vs. 322 $[19-674] \mu \mathrm{g} / \mathrm{kg} / \mathrm{h}, p=0.004)$. A difference in laboratory results between patients resected and those refused surgery could also be noted. Statistical significance was calculated for serum bilirubin, albumin, INR, and platelet count $(p<0.001)$. Patients undergoing surgery were mostly diagnosed with a single nodule, whereas $44 \%$ of the patients receiving different treatment strategies were diagnosed with multifocal disease $(p=0.007)$. However, there was no difference in the size of the largest nodule between these 2 groups. Spleen size was significantly lower in patients undergoing surgery. Patients were considered irresectable due to impaired liver function, anatomy, and other reasons such as age, comorbidities, or denial of surgery. Surgical therapy options were withdrawn due to insufficient functional reserve in 17 patients (LiMAx of 198 [90-247] $\mu \mathrm{g} / \mathrm{kg} / \mathrm{h}$ ). Six patients were put on a waiting list for liver transplantation. In all but 1 patient, who had 
Table 2. Data of patients selected or declined for liver resection

\begin{tabular}{|c|c|c|c|}
\hline & Resected & Not resected & $p$ value \\
\hline Patients & $46(50)$ & $46(50)$ & \\
\hline Age, years & $65(43-81)$ & $65.5(48-88)$ & $0.26^{\mathrm{a}}$ \\
\hline BMI, $\mathrm{kg} / \mathrm{m}^{2}$ & $26(18-46)$ & $27(18-37)$ & $0.65^{\mathrm{a}}$ \\
\hline LiMAx, $\mu \mathrm{g} / \mathrm{kg} / \mathrm{h}$ & $388(127-841)$ & $322(19-674)$ & $0.004^{\mathrm{a}}$ \\
\hline Bilirubin, mg/dL & $0.6(0.2-2.0)$ & $0.95(0.2-7)$ & $<0.001^{\mathrm{a}}$ \\
\hline Albumin, g/dL & $4.4(3.6-5.1)$ & $4.0(2.8-4.8)$ & $<0.001^{\mathrm{a}}$ \\
\hline INR & $1.02(0.88-1.18)$ & $1.15(0.9-2.4)$ & $<0.001^{\mathrm{a}}$ \\
\hline Platelet count, $\times 10^{3} / \mu \mathrm{L}$ & $209(103-534)$ & $149(51-390)$ & $<0.001^{\mathrm{a}}$ \\
\hline Spleen size, $\mathrm{cm}$ & $10.5(6.9-16.0)$ & $12.2(7.0-16.6)$ & $<0.001^{\mathrm{a}}$ \\
\hline Unifocal lesion & $38(82.6)$ & $26(56.5)$ & $0.007^{\mathrm{b}}$ \\
\hline Multifocal lesions & $8(17.4)$ & $20(43.5)$ & \\
\hline Size lesion, $\mathrm{cm}$ & $5.4(1.3-22)$ & $5.0(1-17.4)$ & $0.33^{\mathrm{a}}$ \\
\hline $\mathrm{AFP}, \mu \mathrm{g} / \mathrm{L}$ & $4.9(1.7-21,000)$ & $19.9(2.1-60,500)$ & $0.0024^{\mathrm{a}}$ \\
\hline Decision against resection & & 46 & \\
\hline Functional reserve & & $17(37)^{1,2}$ & \\
\hline Technical/anatomical & & $7(15)$ & \\
\hline General condition & & $16(35)^{3}$ & \\
\hline Listed for transplantation & & $6(13)$ & \\
\hline labMELD & $7(6-13)$ & $8(6-19)$ & $<0.001^{\mathrm{a}}$ \\
\hline BCLC & & & $0.12^{\mathrm{b}}$ \\
\hline 0 & $2(4.3)$ & 0 & \\
\hline A & $20(43.5)$ & $21(45.7)$ & \\
\hline B & $21(47.5)$ & $15(32.6)$ & \\
\hline $\mathrm{C}$ & $3(6.5)$ & $8(17.4)$ & \\
\hline
\end{tabular}

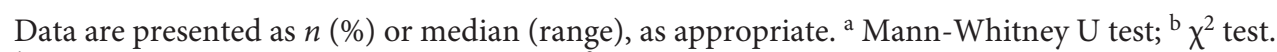

${ }^{1}$ Median LiMAx of 198 (19-247) $\mu \mathrm{g} / \mathrm{kg} / \mathrm{h} .{ }^{2}$ 16/17 patients were diagnosed with cirrhosis; 1 patient showed no signs of liver cirrhosis but suffered from biliary obstruction with consecutive decrease in liver function (LiMAx value of $163 \mu \mathrm{g} / \mathrm{kg} / \mathrm{h}) .{ }^{3} 1$ simultaneous NSCLC, 1 surgery denied, and 2 elderly patients with reduced performance status.

been stated as functionally irresectable, signs of liver cirrhosis were evident. That patient suffered from biliary obstruction with consecutive secondary decrease in liver function (LiMAx value of $163 \mu \mathrm{g} / \mathrm{kg} / \mathrm{h}$ ). Table 2 summarizes detailed data on the resected patients.

\section{Predictors of Functional Resectability}

To evaluate the impact of several liver function parameters on the decision of functional irresectability in our interdisciplinary conference, different parameters were integrated into a ROC analysis. Results of LiMAx testing (AUC 0.97, $p<0.0001$ ), serum bilirubin (AUC 0.78, $p=$ $0.002)$, and albumin $(0.73, p=0.01)$ were identified as strong predictors of insufficient functional liver reserve. ROC analysis yielded a cut-off value of $221 \mu \mathrm{g} / \mathrm{kg} / \mathrm{h}$ for the LiMAx test, resulting in a sensitivity of 0.88 and a specificity of 0.97 (Fig. 1).

\section{Postoperative Outcome}

Histological assessment revealed liver cirrhosis (Ishak score 5-6) in 8 (17\%) resected patients with a median preoperative LiMAx value of 349 [127-512] $\mu \mathrm{g} / \mathrm{kg} / \mathrm{h}$. In 2 of these patients, preoperative imaging and laboratory results showed no signs of liver cirrhosis (age-spleen-platelet ratio index $<9$ [24]) with a normal liver function, resulting in LiMAx values of 481 and $364 \mu \mathrm{g} / \mathrm{kg} / \mathrm{h}$, respectively. When analyzing the complication rates and complication severity grades, patients in the LC group did not experience more complications or higher complication grades according to the Clavien-Dindo classification. Postoperative mortality remained low at $4 \%$. When analyzing individual postoperative complications, such as PHLF, only 3 patients could be detected in the LC group. Overall, just 10 patients presented with PHLF after surgery, 7 with normal liver parenchyma in the histological assessment (NL group) and 9 after major liver resection. In the LC group, however, 2 patients died from PHLF (preoperative LiMAx 127 and 165 $\mu \mathrm{g} / \mathrm{kg} / \mathrm{h}$ ) and were retrospectively appraised functionally irresectable. The median LiMAx value of patients with PHLF was 397 [127-721] vs. 388 [223-814] $\mu \mathrm{g} / \mathrm{kg} / \mathrm{h}$ in those without PHLF. The PHLF rate just reached $22 \%$ in total. Consequently, only resection of $\geq 4$ liver segments and serum bilirubin were predictive for the development of PLHF in multivariate regression analysis (data not shown). Compared to the LC group, patients in the NL group presented with a significantly shorter stay in intensive care, 


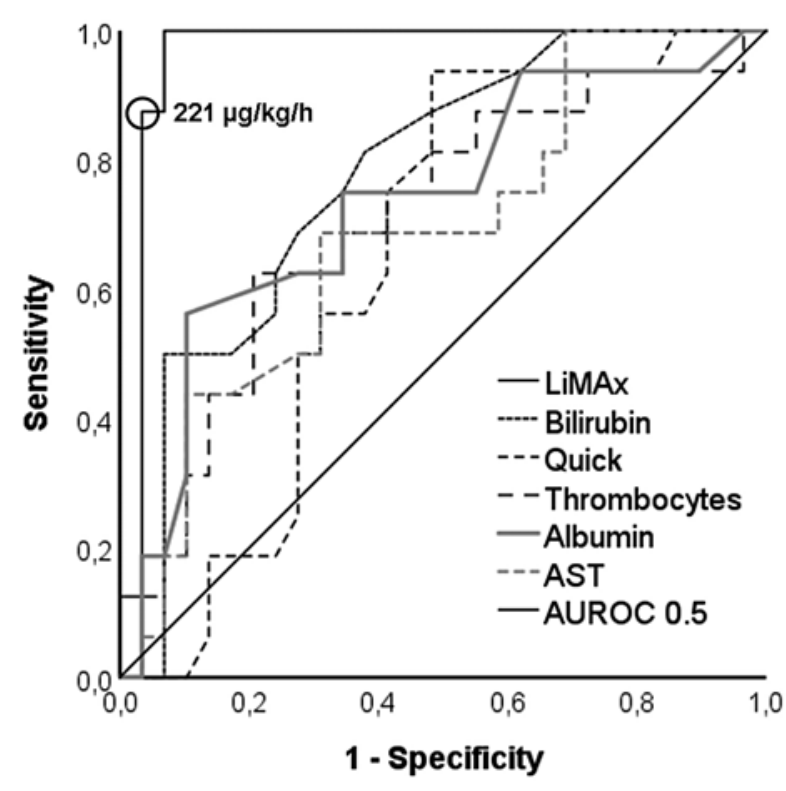

Fig. 1. Receiver operating characteristic (ROC) analysis of risk factors for the prediction of functional irresectability. Calculated AUC of preoperative LiMAx values $(\mu \mathrm{g} / \mathrm{kg} / \mathrm{h})$, bilirubin $(\mathrm{mg} / \mathrm{dL})$, Quick (equivalent to dilution of normalized plasma in \%), thrombocytes $\left(\times 10^{3} / \mu \mathrm{L}\right)$, albumin $(\mathrm{mg} / \mathrm{dL})$, and AST $(\mathrm{U} / \mathrm{L})$. The best cutoff for LiMAx is shown. AUROC, area under the ROC curve; AST, aspartate transaminase.

although no difference in length of hospital stay could be observed between groups. Median preoperative LiMAx values obtained from all resected patients $(n=12)$ within the LC group were 349 [127-512] $\mu \mathrm{g} / \mathrm{kg} / \mathrm{h}$, and 6 patients with favorable LiMAx results received major hepatectomy, being discharged after 11 (5-28) days. For detailed data on postoperative outcome, see Table 3.

\section{Discussion}

In the present study, we demonstrate that preoperative evaluation of functional reserve in HCC using the LiMAx test enables valid assessment of functional resectability. LiMAx values were identified as independent factors for the presence of liver cirrhosis. To safely perform resection surgery on patients with liver cirrhosis a cut-off value of $221 \mu \mathrm{g} / \mathrm{kg} / \mathrm{h}$ was identified in ROC analysis. Applying this cut-off value, we observed no difference in postoperative morbidity and mortality between patients with and without liver cirrhosis, at a low rate of PHLF. To the best of our knowledge, this is the second study providing favorable data on the LiMAx test as a preoperative tool to stratify HCC patients for resection surgery [16].

Although the extent of liver fibrosis is valuable in the prediction of PHLF [25], several factors, such as the etiol- ogy of chronic liver disease amongst others, seem to have an impact on the actual liver function, resulting in higher enzymatic liver function capacity within individuals [26]. The lack of accurate preoperative tests which predict postoperative outcome before hepatectomy was the motivation for the development of a bedside breath test with ${ }^{13} \mathrm{C}$-methacetin [18]. Previous studies have shown the LiMAx test to be an independent predictor of postoperative liver failure and mortality [16-18]. The evaluation of diagnostic power consequently revealed a high individual validity, as shown during area under receiver operating characteristic curve (AUROC) analysis [18]. The critical point for PHLF was identified at a postoperative LiMAx $<85 \mu \mathrm{g} / \mathrm{kg} / \mathrm{h}$, while LiMAx results $>150 \mu \mathrm{g} / \mathrm{kg} / \mathrm{h}$ allow postoperative patient transfer to a normal ward [15]. Normal values were retrieved from a group of healthy volunteers and determined at LiMAx $>315 \mu \mathrm{g} / \mathrm{kg} / \mathrm{h}$ [18]. In our study, LiMAx values were an independent factor for the presence of liver cirrhosis in multivariate analysis but not predictive of PHLF. The overall PHLF and mortality rates in this study were slightly lower than those in an equal patient cohort that also received dynamic liver function assessment prior to HCC resection surgery [16]. However, the most likely explanation for a similar rate of PHLF in both the LC and NL groups is a more aggressive resection of significantly larger tumors in the NL patients compared to their LC counterparts.

Since August 2013, the LiMAx test has become available in routine preoperative evaluation at our department. Since chronic liver disease and HCC are closely associated, all patients diagnosed with HCC are presented in an interdisciplinary conference, where the decision to perform liver function analysis is made. Following that, LiMAx values are interpreted, aiding the decision for or against surgical treatment. Previously published data allowed the resection of up to 4 liver segments in cases of normal liver function (LiMAx $>315 \mu \mathrm{g} / \mathrm{kg} / \mathrm{h}$ ) [17]. In contrast, patients with impaired liver function (preoperative LiMAx $<140 \mu \mathrm{g} / \mathrm{kg} / \mathrm{h}$ ) or portal hypertension shall be refused surgery, as they are prone to developing PHLF after minor liver resection as well as any abdominal surgery $[16,17]$. In our experience, LiMAx values below that range must be considered an absolute contraindication for resection surgery in patients with liver cirrhosis and should consequently be implemented into therapeutic algorithms, as one patient with preoperative enzymatic liver function capacity of only $127 \mu \mathrm{g} / \mathrm{kg} / \mathrm{h}$ died of postoperative liver failure.

However, the most challenging decisions are those for patients with an intermediate liver function (140-315 $\mu \mathrm{g} /$ $\mathrm{kg} / \mathrm{h}$; limited hepatic impairment). In these patients, safety of resection must be evaluated individually according to the resection strategy [17]. Until this year, published data were obtained from patients without chronic liver disease. Thus, previously determined cut-off values shall not apply to patients diagnosed with HCC and underly- 
Table 3. Perioperative data of HCC patients with and without liver cirrhosis

\begin{tabular}{lccl}
\hline & LC group & NL group & $p$ value \\
\hline Resected patients & $13(30)$ & $33(70)$ & $0.004^{\mathrm{a}}$ \\
Age, years & $64(43-79)$ & $65(47-81)$ & $\mathrm{ns}$ \\
LiMAx, $\mu \mathrm{g} / \mathrm{kg} / \mathrm{h}$ & $328(127-512)$ & $431(242-841)$ & $0.030^{\mathrm{a}}$ \\
Unifocal & $9(69.2)$ & $20(60.6)$ & $\mathrm{ns}$ \\
Size lesion, cm & $3.9(1.6-7.5)$ & $6.5(1.3-22)$ & $0.014^{\mathrm{a}}$ \\
Outside Milan criteria & $8(54)$ & $23(70)$ & $0.73^{\mathrm{b}}$ \\
PHLF & $10(77)$ & $26(78.8)$ & \\
$\quad 1(8)$ & $5(15.2)$ & \\
$\quad$ None & $0(0)$ & $1(3)$ & \\
$\quad$ Grade A & $2(15.4)$ & $1(3)$ & $\mathrm{ns}$ \\
$\quad$ & & & \\
Grade B & $1(8)$ & $2(6)$ & $\mathrm{ns}$ \\
Clavien-Dindo & $2(15)$ & $0(0)$ & $0.042^{\mathrm{a}}$ \\
$\quad$ Grade IIIa-IVb & $3(0-20)$ & $1(0-14)$ & $\mathrm{ns}$ \\
$\quad$ Grade V & $9(5-28)$ & $12(6-33)$ & \\
LOI, days & & & \\
LOS, days & & & \\
\hline
\end{tabular}

Data are presented as $n$ (\%) or median (range), as appropriate. LC group, liver cirrhosis group; NL group, normal liver group; LOI, length of ICU stay; LOS, length of hospital stay. ${ }^{a}$ Mann-Whitney U test; ${ }^{\text {b }}$ Fischer exact test. ing liver disease. Recently, Blüthner et al. [16] demonstrated superiority of future remnant liver function to future liver remnant volume in the prognosis of PHLF in a high-risk subgroup of HCC patients. However, future remnant liver function was calculated using LiMAx as well as indocyanine green plasma disappearance rate. Furthermore, no cut-off values that might be applicable to clinical decision making were provided. In this study, we demonstrate satisfying surgical results in HCC patients with LiMAx values $>221 \mu \mathrm{g} / \mathrm{kg} / \mathrm{h}$ in the absence of major hyperbilirubinemia and portal hypertension (bilirubin $<2 \mathrm{mg} / \mathrm{dL}$, no splenomegaly or thrombocytes < $100,000 / \mu \mathrm{L})$. Based on these results, 8 out of 13 HCC patients in the LC group staged outside the Milan criteria underwent oncologically favorable liver resection. Hence, the LiMAx test enables surgeons to offer radical resection to those they may have previously declined. Whether the routine preoperative application of the LiMAx test increases HCC patients' perioperative safety remains to be elucidated. Although there are prospective data showing a decrease in postoperative morbidity of patients who received LiMAx testing prior to resection of intrahepatic tumors in healthy liver parenchyma, a significant decrease in PHLF or postoperative mortality cannot be shown in this study as it lacks a matched cohort for comparison [15]. Of note, a correlation between impaired liver function capacity and early recurrence of HCC after resection surgery has been demonstrated. Therefore, preoperative LiMAx testing might not only be a valuable tool in the prediction of surgical, but ultimately of oncological outcome of HCC patients [27].
This study has several limitations. First, since this is an uncontrolled, retrospective study, patient selection bias cannot be ruled out, as clinicians are more likely to recommend operative therapy to younger, healthier patients who would be expected to tolerate surgery better than older patients of poorer performance status. Still, in our cohort, patients with liver cirrhosis and resection surgery were of the same age as those with normal liver parenchyma. Second, although preoperative hepatic function and prognosis of the residual function is important, intraoperative factors such as blood loss and warm ischemic time that may have a deleterious effect on postoperative function should also be considered. The preoperative LiMAx test cannot predict unfavorable intraoperative events, such as massive bleeding and/or the necessity of hepatic inflow control. Therefore, it may be sensible to consider a "margin of error" for patients in whom a significant hepatic event is anticipated. Residual liver function is an essential but not unique limitation of hepatectomy. Therapeutic decisions should integrate multiple diagnostic parameters and clinical factors. Third, the LiMAx cut-off value needs to be further validated in larger patient cohorts with prospective studies correlating predicted postoperative volume and function in liver cirrhosis with actual values in the postoperative period.

In conclusion, the evaluation of preoperative liver function by the LiMAx test enables effective preoperative decision making to select patients who can safely benefit from HCC resection. Together with interdisciplinary conference, postoperative mortality and morbidity remains low, even in the presence of liver cirrhosis. 


\section{Acknowledgments}

The Authors wish to thank Katrin Bischof, Sina Reith, and Martina Breunig for the performance of liver function tests.

\section{Statement of Ethics}

All procedures performed in this study involving human participants were in accordance with the ethical standards of the Institutional Reviewer Board (approval No. 20190603 01) and with the 1964 Helsinki Declaration and its later amendments or comparable ethical standards. Informed consent for LiMAx ${ }^{\circledR}$ testing was obtained from all individual participants included in the study. Informed consent was also obtained from patients receiving resection surgery.

\section{Disclosure Statement}

The authors have no conflicts of interest to disclose.

\section{Funding Sources}

This work did not receive any specific grant or funding.

\section{Author Contributions}

J.F.L.: study conception and design, analysis and interpretation of data, and drafting of the manuscript. F.A.: analysis and interpretation of data and drafting of the manuscript. G.S. and D.S.: acquisition of data and critical revision of the manuscript. I.K., S.L., O.G., and A.G.: analysis and interpretation of data and critical revision of the manuscript.

\section{References}

1 Hsu CY, Liu PH, Hsia CY, Lee YH, Nagaria TS, Lee RC, et al. Surgical Resection is Better than Transarterial Chemoembolization for Patients with Hepatocellular Carcinoma Beyond the Milan Criteria: A Prognostic Nomogram Study. Ann Surg Oncol. 2016 Mar;23(3):994-1002.

2 Vitale A, Burra P, Frigo AC, Trevisani F, Farinati F, Spolverato G, et al.; Italian Liver Cancer (ITA.LI.CA) group. Survival benefit of liver resection for patients with hepatocellular carcinoma across different Barcelona Clinic Liver Cancer stages: a multicentre study. J Hepatol. 2015 Mar;62(3):617-24.

3 Liu H, Wang ZG, Fu SY, Li AJ, Pan ZY, Zhou WP, et al. Randomized clinical trial of chemoembolization plus radiofrequency ablation versus partial hepatectomy for hepatocellular carcinoma within the Milan criteria. Br J Surg. 2016 Mar;103(4):348-56.

4 Roayaie S, Jibara G, Tabrizian P, Park JW, Yang J, Yan L, et al. The role of hepatic resection in the treatment of hepatocellular cancer. Hepatology. 2015 Aug;62(2):440-51.

5 Menahem B, Lubrano J, Duvoux C, Mulliri A Alves A, Costentin C, et al. Liver transplantation versus liver resection for hepatocellular carcinoma in intention to treat: an attempt to perform an ideal meta-analysis. Liver Transpl. 2017 Jun;23(6):836-44.

6 Sasaki K, Shindoh J, Margonis GA, Nishioka Y, Andreatos N, Sekine A, et al. Effect of Background Liver Cirrhosis on Outcomes of Hepatectomy for Hepatocellular Carcinoma. JAMA Surg. 2017 Mar;152(3):e165059.

7 Schoenberg MB, Bucher JN, Vater A, Bazhin AV, Hao J, Guba MO, et al. Resection or Transplant in Early Hepatocellular Carcinoma. Dtsch Arztebl Int. 2017 Aug;114(31-32): 519-26.

8 Schneider PD. Preoperative assessment of liver function. Surg Clin North Am. 2004 Apr; 84(2):355-73.

9 Yang T, Zhang J, Lu JH, Yang GS, Wu MC, Yu WF. Risk factors influencing postoperative outcomes of major hepatic resection of hepatocellular carcinoma for patients with underlying liver diseases. World J Surg. 2011 Sep; 35(9):2073-82.
10 van den Broek MA, Olde Damink SW, Dejong $\mathrm{CH}$, Lang $\mathrm{H}$, Malagó $\mathrm{M}$, Jalan $\mathrm{R}$, et al. Liver failure after partial hepatic resection: definition, pathophysiology, risk factors and treatment. Liver Int. 2008 Jul;28(6):767-80.

11 Fu C, Liu N, Deng Q, Li X, Ma K, Bie P. Radiofrequency ablation vs. surgical resection on the treatment of patients with small hepatocellular carcinoma: a system review and meta-analysis of five randomized controlled trials. Hepatogastroenterology. 2014 Sep; 61(134):1722-9.

12 Schroeder RA, Marroquin CE, Bute BP, Khuri $\mathrm{S}$, Henderson WG, Kuo PC. Predictive indices of morbidity and mortality after liver resection. Ann Surg. 2006 Mar;243(3):373-9.

13 Lau H, Man K, Fan ST, Yu WC, Lo CM, Wong J. Evaluation of preoperative hepatic function in patients with hepatocellular carcinoma undergoing hepatectomy. Br J Surg. 1997 Sep; 84(9):1255-9.

14 Wakabayashi H, Ishimura K, Izuishi K, Karasawa Y, Maeta H. Evaluation of liver function for hepatic resection for hepatocellular carcinoma in the liver with damaged parenchyma. J Surg Res. 2004 Feb;116(2):248-52.

15 Stockmann M, Vondran FW, Fahrner R, Tautenhahn HM, Mittler J, Bektas H, et al.; Collaborative Fast-track Liver Study Group. Randomized clinical trial comparing liver resection with and without perioperative assessment of liver function. BJS Open. 2018 Jun;2(5):301-9.

16 Blüthner E, Jara M, Shrestha R, Faber W, Pratschke J, Stockmann M, et al. The predictive value of future liver remnant function after liver resection for HCC in noncirrhotic and cirrhotic patients. HPB (Oxford). 2019 Jul;21(7):912-22.

17 Stockmann M, Lock JF, Malinowski M, Niehues SM, Seehofer D, Neuhaus P. The LiMAx test: a new liver function test for predicting postoperative outcome in liver surgery. HPB (Oxford). 2010 Mar;12(2):139-46.

18 Stockmann M, Lock JF, Riecke B, Heyne K, Martus P, Fricke M, et al. Prediction of postoperative outcome after hepatectomy with a new bedside test for maximal liver function capacity. Ann Surg. 2009 Jul;250(1):119-25.
19 Jara M, Bednarsch J, Valle E, Lock JF, Malinowski M, Schulz A, et al. Reliable assessment of liver function using LiMAx. J Surg Res. 2015 Jan;193(1):184-9.

20 Lubner MG, Pickhardt PJ. Multidetector Computed Tomography for Retrospective, Noninvasive Staging of Liver Fibrosis. Gastroenterol Clin North Am. 2018 Sep;47(3): 569-84

21 Lurie Y, Webb M, Cytter-Kuint R, Shteingart S, Lederkremer GZ. Non-invasive diagnosis of liver fibrosis and cirrhosis. World J Gastroenterol. 2015 Nov;21(41):11567-83.

22 Dindo D, Demartines N, Clavien PA. Classification of surgical complications: a new proposal with evaluation in a cohort of 6336 patients and results of a survey. Ann Surg. 2004 Aug;240(2):205-13.

23 Rahbari NN, Garden OJ, Padbury R, BrookeSmith M, Crawford M, Adam R, et al. Posthepatectomy liver failure: a definition and grading by the International Study Group of Liver Surgery (ISGLS). Surgery. 2011 May; 149(5):713-24.

24 Kim BK, Kim SA, Park YN, Cheong JY, Kim HS, Park JY, et al. Noninvasive models to predict liver cirrhosis in patients with chronic hepatitis B. Liver Int. 2007 Sep; 27(7):969-76.

25 Nishio T, Taura K, Koyama Y, Tanabe K, Yamamoto G, Okuda Y, et al. Prediction of posthepatectomy liver failure based on liver stiffness measurement in patients with hepatocellular carcinoma. Surgery. 2016 Feb;159(2): 399-408.

26 Malinowski M, Jara M, Lüttgert K, Orr J, Lock JF, Schott E, et al. Enzymatic liver function capacity correlates with disease severity of patients with liver cirrhosis: a study with the LiMAx test. Dig Dis Sci. 2014 Dec;59(12):298391.

27 Blüthner E, Bednarsch J, Malinowski M, Binder P, Pratschke J, Stockmann M, et al. Dynamic liver function is an independent predictor of recurrence-free survival after curative liver resection for $\mathrm{HCC}$ - A retrospective cohort study. Int J Surg. 2019 Nov;71: 56-65. 